\title{
MÍMICA, DIFERENÇA E REPETIÇÃO
}

\author{
Marcelo Mendes de Souza
}

Doutorando em Literatura - UFSC

Resumo: Esse artigo pretende discutir o conceito de mímica de Homi K. Bhabha dentro de um contexto mais amplo, ulterior ao contexto dos estudos culturais e pós-coloniais, aproximando dele outros conceitos, tais como os estabelecidos por Gilles Deleuze em Diferença e repetição, entre outros textos, além de outros nomes, tais como Silviano Santiago, Jorge Luis Borges, Franz Kafka e Giorgio Agamben. Como uma espécie de conclusão prévia, ao final, o artigo confronta o conceito freudiano-marxista de Bhabha às Cinco proposições sobre a psicanálise, texto de Gilles Deleuze, de 1973 - desdobrando as discussões sobre psicanálise propostas em $O$ Anti-Édipo, do mesmo autor.

Palavras-chave: Estudos Culturais; Homi K. Bhabha; Mímica; Gilles Deleuze.

\begin{abstract}
This article addresses Homi K. Bhabha's concept of mimicry in a broader context, other than that of cultural studies and post-colonial studies, bringing together other concepts, such as that of Gilles Deleuze in Difference and repetition, among other texts, and other names, such as Silviano Santiago, Jorge Luís Borges, Franz Kafka and Giorgio Agamben. As a partial conclusion, the article intends to oppose Bhabha's freudian-marxist view to Five propositions on Psychoanalysis (1973), Gilles Deleuze's text about Psychoanalysis published right after his book The Anti-Oedipus.
\end{abstract}

Keywords: Cultural Studies; Homi K. Bhabha; Mimicry; Gilles Deleuze. 
(...) substituímos as articulações do real pelos modos só utilitários de agrupamento. Mas não é isso o mais importante; a utilidade não pode

fundar o que a torna possivel.

(Gilles Deleuze, A concepção de diferença em Bergson)

É sempre o imitador quem cria seu modelo e o atrai. (Gilles Deleuze, Introdução: Rizoma)

No apagar das luzes de um teatro colonial, ainda é possível olhar para esses gatos pardos: colonizador e colonizados. Resquícios de um processo "civilizatório" e partes do vocabulário desse mesmo processo, esses dois pólos se encontram, no conceito de mímica (mimicry) formulado por Homi K. Bhabha, em uma imagem especular, na qual o "real", a imagem a partir da qual o espelho especula, parece ser o europeu, mais especificamente o inglês, e a imagem gerada, o oriental, no caso específico, o indiano. A mímica opera por repetição, a repetição do mesmo diferenciado; em tese, seria a maneira pela qual o colonizado se apropria do discurso e dos modos de vida dos colonizadores, uma espécie de "repetição de presença parcial", pois a parte que falta é exatamente essa que torna possível ver que se está, no caso específico tratado por Bhabha (1998, p. 134), em frente a um indiano anglicizado, que é diferente ("quase o mesmo, mas não exatamente") de um inglês. É na comicidade dessa repetição, a qual Bhabha nomeia "desvio cômico dos altos ideais da imaginação colonial" (ibid., p. 129), que se dá a possibilidade de desestabilização de um discurso colonizador (ambivalente) e, conseqüentemente, de sua autoridade.

Mímica é uma espécie de repetição, e toda repetição, segundo Gilles Deleuze, pressupõe uma singularidade (insubstituível): “[...] somente em relação à suposta identidade de um conceito genérico que a diferença específica é tida como maior. Bem mais, é em relação à forma de identidade no conceito genérico que a diferença vai até a oposição, é impelida até a contrariedade" (DELEUZE, 1988, p. 69). Aqui poderíamos pensar como conceito genérico a figura do colonizador, a figural ideal do colonizador, assentada que está, em um determinado momento histórico, em relação a sua identidade - ou a uma identidade. O lugar da repetição mímica, então, seria esse espaço da identidade, no qual se pressupõe uma identidade ocidental como inicial, ou melhor, identidade a partir da qual se produz a alteridade. Em outras palavras, é a partir da centralidade de uma determinada identidade, concebida de forma arbitrária, legal, a partir de uma relação de poder, que se torna possível o outro. A lei pressupõe transgressão - e aqui Bhabha pode encontrar, entre outras linhas, Deleuze (de Diferença e repetição) e Bataille (em $O$ erotismo, por exemplo). Em síntese: "sob todos os aspectos, a repetição é a transgressão. Ela põe a lei em questão, denuncia seu caráter nominal ou geral em proveito de uma realidade profunda e mais artística" (DELEUZE, 1988, p. 69).

De certa forma, o que Bhabha nos propõe é uma espécie de lei da supremacia do colonizador e sua analogia, o mundo da representação do colonizado segundo esse imaginário. Ou seja, a visão de Bhabha está assentada em uma metafísica da generalidade: genérico (colonizador) versus ser (colonizado) - que, por sua vez, pressupõe a diferença arbitrária entre superior e inferior. A cópia do colonizado é sempre (e aqui estamos diante de um recorte temporal e localizado) feita a partir do modelo "original", o colonizador. Primeiro, há a questão da linguagem: segundo Deleuze (1988, p. 457), as potências da repetição são as potências da linguagem. 
Portanto, uma vez que se imbui o outro de sua linguagem, cria-se a possibilidade de transgressão dentro de seu próprio sistema. Podemos ampliar isso à "cultura"; uma cultura ocidental, por exemplo, só pode ser transgredida dentro dela mesma, pois a diferença que há, nesse caso, entre a cultura ocidental (de forma genérica) e uma cultura oriental (de forma localizada) é uma diferença de natureza, pois não há, senão artificialmente, o espaço de identidade pressuposto na diferença que vai à oposição, que transgride. Segundo, Bhabha (1998, p. 134) considera a repetição um "desvio cômico dos altos ideais da imaginação colonial a seus baixos efeitos literários miméticos”; da mesma forma, Deleuze considera que as potências da repetição são, também, as potências da arte - lembrando que, segundo o autor, repetição é transgressão.

Bhabha reconhece que a questão da representação da diferença está atrelada à autoridade, ao poder, mas pensa na mímica como uma estratégia, e não como parte de um sistema fundado por sua oposição. Aparentemente, seu conceito de mímica está envolvido em outro, psicológico ou psicologizante, que inclui o desejo como um dos elementos centrais e certa tensão entre a "ilusão" da diferença e a "realidade" da semelhança. A idéia é que as representações estereotipadas (exageradas), que é como podemos entender a mímica, trairiam o senso de identidade própria do colonizador e que a ansiedade gerada por isso abriria um espaço de resistência para o colonizado. Obviamente, há que se pensar no ideal de uma identidade colonizada em seu reconhecimento, ou seja, supor uma identidade a partir da qual as diferenças são produzidas e contra a qual se voltam. Como todo discurso de base psicológica, a idéia é que há uma cura, um Édipo a partir do qual todo desvio e toda possibilidade de retorno são mapeados. A idéia, talvez estratégica, é determinar de forma clara esses pólos de "diferenciação" para que se torne possível uma ação efetiva; primeiro, agindo por bipartição: colonizado e colonizador; depois, estabelecendo metafísicas pragmáticas do tipo superior/inferior, sob a proteção do distanciamento histórico e da construção dessas metafísicas a partir do ponto de vista dos excluídos. Não há espaço para ambigüidades e questões de identidade, como a mímica inversa: o colonizado como modelo. Para isso é possível pensar, por exemplo, em determinada arte moderna européia, que tem como modelo certa representação da diferença, tal qual se concebe a partir desse "mesmo" constituído, no caso o colonizador, ou mesmo, no fascínio diante de uma literatura "colonizada", tal qual a de Borges, por exemplo, que devolve o exotismo ao seu criador, o europeu ${ }^{1}$.

Em texto escrito por ocasião dos dez anos de morte de Jorge Luis Borges, $A$ ameaça do lobisomem, Silviano Santiago estabelece o limite do pensamento europeu a partir do encontro com o pensamento latino-americano, colocando Borges como uma de suas fronteiras reconhecidas e legitimadas. Ou seja, o pensamento europeu encontraria, em vez de uma reprodução, um espaço de expansão. O europeu, inicialmente, entenderia essa expansão de forma negativa, manifestada pelo racismo, pela visão excêntrica que tinha do colonizado, mas, em um segundo momento, ficaria espantado diante de sua própria criação, ao encarar o exotismo em formas, por exemplo, literárias. Muito mais do que um efeito cômico, esse retorno realimentaria o limite do pensamento europeu, fazendo-o conviver com suas próprias fronteiras (e, por exemplo, em Foucault, falar da necessidade de se traçar os limites dessa maneira de pensar). A idéia é que a arte latino-americana faz conviver o mesmo e o outro em um solo único, e essa "sempre foi a razão material da cultura colonizada" (SANTIAGO, 2004, p. 219). Na América Latina, a questão da convivência do outro e do mesmo (poderíamos dizer, do colonizado 
e do colonizador) moldaria toda a cultura, inclusive nos momentos de se questionar o eurocentrismo ou, por outro lado, afirmar-se cosmopolita, "universal". A idéia, acredito, é que não há cultura latino-americana sem essa espécie de hibridismo, ou seja, a cultura colonizada, no caso específico da América Latina, seria, desde seu cerne, essa figura monstruosa, bifurcada, na qual convivem Europa e América, o mesmo e o outro. Do ponto de vista europeu: exotismo, diferença; do ponto de vista, por exemplo, brasileiro: identificação e reverência.

Mais do que marcar as diferenças de colonização, que sem dúvida existem, a visão de Silviano Santiago sobre a cultura latino-americana, colonizada, pressupõe um espaço comum, que pode ser tanto a língua do colonizador, como seus meios de expressão (a arte, a literatura, o romance, etc.). Pode ser também o próprio alicerce dessa cultura, não apenas como estratégia de resistência, mas como ato fundador da restrição que possibilitaria essa mesma resistência. A cultura colonizada não seria um começo, mas um segundo começo, ou um re-começo, a fundação mesmo da lei que faz ver essa repetição, ou que a estabelece, a origem de uma série que torna possível a mímica de Bhabha. Em outras palavras: a criação simultânea - e bifurcada - de original e cópia, dentro de um determinado sistema regido por leis, por relações de força. Nesse espaço, poderíamos colocar a mímica como essa espécie de "acordo irônico" entre as partes envolvidas, como diria Bhabha. No entanto, ela continuaria como a representação de uma diferença que não é fundamentalmente um processo de recusa, mas parte da (re)formação dessa cultura disforme, que traça seus contornos a partir do encontro com o outro. Ou seja, não haveria necessariamente intencionalidade por trás das semelhanças e repetições, sendo que as semelhanças, segundo Deleuze junto a Aristóteles, só podem ser pensadas a partir da repetição, da criação de séries que estabelecem, na repetição mesmo, o semelhante, não por uma questão divina, absoluta, fundadora, original, mas como parte desse sistema. A idéia de Bhabha parece abrir uma trincheira onde há de antemão um buraco, reinventa a roda para fazê-la deslizar pelo teatro colonial, fazendo notar o óbvio para utilizá-lo de forma lancinante numa espécie de luta de classes reorganizadas segundo critérios coloniais.

Feita a introdução, tomemos como exemplo o conto Ein Bericht für eine Akademie (Informação para os senhores acadêmicos, na tradução de Guimarães, de 1977, ou Informação para uma academia, na tradução mais literal do título, de 2000), de Franz Kafka, utilizando-o como máquina literária para dar conta do problema aqui estabelecido: a idéia das representações estereotipadas, que é como podemos entender a mímica, traindo o senso de identidade própria do colonizador e a ansiedade gerada por esse fato, a qual abriria um espaço de resistência para o colonizado. Os termos se deslocam, então, segundo a dicotomia estabelecida pelo conto, a saber: trata-se da história de um macaco que é convidado a contar para um grupo de acadêmicos a trajetória que descreveu desde sua existência simiesca até sua humanização, o que faz colidir estes extremos: homem e animal. Pedro, o Vermelho (é esse o nome do personagem) conta (pois é ele o narrador dessa história) que, depois de ter sido atingido por dois tiros e confinado, não vê outra saída senão se tornar humano. A distância do que foi esse Macaco, que agora reporta sua humanização, equivale à distância a qual os humanos guardamos de algo semelhante a ele - uma vez que essa condição primitiva faz "cócegas nos calcanhares de todo aquele que pisa sobre a terra, seja o pequeno chipanzé, seja o grande Aquiles" (KAFKA, 1977, p. 144). Pedro funcionaria, então, não apenas como um espelho da condição simiesca do humano, mas como a demonstração 
do limite de uma condição humana. Em outras palavras: Pedro devolveria uma imagem possível da humanidade, que, por outro lado e livre desse termo da série (a imitação que o macaco faz do homem se inscreveria em uma série na qual o humano, como base dessa mímica, seria possível), parece tão unívoca, estabelecida - o mesmo sem o outro pode parecer absoluto.

Há a comicidade da situação: o inusitado substitui o lugar-comum. A presença do macaco falando diante dos acadêmicos, principalmente sua fala, ultrapassa um limiar aparentemente bem constituído, que é Homo sapiens. Usando os termos de Deleuze e Guatarri, podemos chamar esse encontro de um devir homem no animal - ou, dentro da mesma idéia, de devir animal no homem (o espaço seria o mesmo). E os devires são o contrário de uma garantia ontológica: eles produzem desterritorializações absolutas, radicais. Nas palavras de Agamben, quando as diferenças entre homem e animal desvanecem "and the two terms collapse upon each other - as seems to be happening today - the difference between being and the nothing, licit and illicit, divine and demonic also fades away, and in its place something appears for which we seem to lack even a name"2 (AGAMBEN, 2004, p. 22). Nesse exato momento, nesse ponto vazio, torna-se possível questionar o ser humano - pensando que também a distinção entre humano e não-humano, humano e macaco, desaparece. $\mathrm{O}$ que a comicidade do conto nos impõe, em sua literalidade, é uma desterritorialização. Suas implicações, ainda na esteira do pensamento de Agamben, vão além de questões teológicas e filosóficas: chegam ao âmbito político, ético e legal. Nesse ponto, falando de uma maneira mais generalizada, existe entre o mesmo e o outro uma área de indiferenciação, um aberto. Por isso é tão difícil, em determinado momento, distinguir um homem de um macaco.

Partindo dessa generalização de uma idéia que pode ser retirada do conto de Kafka, podemos pensar a colisão de dois mundos como o estabelecimento de uma área de devir, uma pista de mão dupla. Entre o mesmo e o outro, podemos pensar nesse entrecho que, a partir de seu encontro, os une - no mesmo ponto em que os separa. Esse espaço, para voltarmos ao teatro colonial, seria o da ambivalência de um discurso colonial - não apenas aquela que se estabelece na idéia expansionista e civilizatória associada a esse discurso, mas também no simples encontro entre essas diferenças, que, nessa colisão, vão se constituindo como tal. Em outras palavras, o encontro entre esses dois termos possibilita sua exceção, a tal ameaça entrevista na mímica de Bhabha. A mímica do macaco de Kafka, que repete algumas maneiras humanas apesar de preso a sua fachada simiesca, representa a ameaça das fronteiras de um (ser) humano, fragilmente constituído em seu isolamento, da mesma forma que um texto colonial, produzido dentro dos parâmetros ocidentais (ou seja, do colonizador) - em sua língua e formas de expressão -, pode ameaçar, por fazer notar essa diferença (que nada mais é que esse espaço conformado pelo "encontro", quase o mesmo, mas não exatamente), uma idéia constituída do mesmo, do ocidental como o centro do mundo, tal qual se organiza no período colonial (e muitas vezes se reproduz nas formas de dominação contemporâneas).

Talvez esse não seja o melhor exemplo para se falar do conceito de Bhabha, uma vez que há diferenças entre o homem e o macaco que passam pelas articulações do real, como o polegar opositor. Podemos distinguir melhor o que o autor conceitua como mímica se pensarmos que esse ato ambivalente de diferenciação e recusa traz em si dois pontos diferentes e complementares: a repetição e a diferença. Diferentes, porque a repetição pressupõe o desaparecimento de um dos termos (o mesmo ou o outro) para 
que seja possível, ao passo que a diferença trata de coexistência - o passado no presente, o mesmo no outro. A diferença se inscreveria, segundo a visão de Deleuze sobre a obra de Bergson ${ }^{3}$, no espírito que a observa. No entanto, a diferença apareceria como o imprevisível, a indeterminação - no caso de Bhabha (a mímica como ameaça ao discurso colonial), a diferença só pode ser constatada em termos de memória -, o que tornaria difícil seu uso estratégico, uma vez que não se poderia prever suas conseqüências ou desdobramentos. Em outras palavras, a diferença em Bergson não conta com o recurso da finalidade, como em Platão, que a teria como guia para medir as partes que colidem o Bem, ou em Bhabha, cuja medida se dá a partir de uma possibilidade de ameaça ao colonizador. A visão de Bergson não parte de contradição, alteridade ou da idéia de negativo, "visões que incidem sobre ela apenas de fora", mas da diferenciação como uma espécie de virtualidade que se atualiza: o homem se diferencia, mas se diferencia sobre si mesmo (o colonizador é a constituição histórica de um vital sobre o qual repousam as possibilidades de mudança, entre elas o colonizado; no entanto, é sobre esse plano comum que se dá a diferença).

Para levar ao extremo essa idéia da convivência dos dois pólos no processo de diferenciação (por exemplo, o passado no presente), tomemos o conto de Jorge Luis Borges Pierre Menard, autor del Quijote. Resumidamente, esse conto narra a história de um autor cujo grande projeto teria sido escrever o Quixote, literalmente, palavra por palavra. O que acontece é esse mesmo processo de diferenciação conceituado pela leitura de Deleuze (Bergson): "El texto de Cervantes y el de Menard son verbalmente idénticos, pero el segundo es casi infinitamente más rico. (Más ambiguo, dirán sus detractores; pero la ambigüedad es una riqueza.)"4 (BORGES, 1996). Cervantes permanece verbalmente intacto; a diferença se dá no espírito que o observa, detratores ou não, e dentro de si mesmo, ou melhor: tendo como base o próprio texto, potencializado pela mera repetição. Nesse caso, a negação de Cervantes, de seu texto aqui tomado como um termo "real", por Menard, como outro termo "real", é a realização de uma virtualidade que contém ao mesmo tempo os dois termos. Não há negação entre um e outro: trata-se do mesmo texto associado a nomes e a entornos diferentes, observado por espíritos diferentes, quer seja o narrador, que tende arbitrariamente para Menard, quer sejam seus denominados detratores, que $o$ consideram ambígüo (que seria a qualidade atestada por Bhabha, assim como pelo narrador do conto, como a riqueza do texto colonial). Pierre Menard seria, então, "o visível Outro no Mesmo, aquele que, pela escrita da memória, diz que a Europa é aqui na América Latina" (SANTIAGO, op. cit., p. 219). A arte colonial poderia ser representada por esse personagem, se aceitarmos que, segundo Silviano Santiago, a coexistência entre o mesmo e outro seria sempre "razão material da cultura colonizada" (id.).

Há uma espécie de linha sensata aqui, um lugar a partir do qual podemos colocar alguns termos que se assemelham, ainda que, nesse breve panorama, não tenhamos nos certificado das distâncias e dos acidentes possíveis. Essa linha descreve uma espécie de genealogia esquizofrênica da idéia de diferença. Melhor, a idéia de que diferença e semelhança se entrelaçam, completam, confundem. O termo principal aqui parece ser diferença, mas, somadas as perspectivas, estamos chegando perto do conceito de mímica para Bhabha. Tanto Deleuze quanto Bergson e Borges parecem retirar da diferença a ontologia, somando a ela sua contra-cara. A diferença não apenas não é transcendental, como é parte de um mecanismo de diferenciação, que passa por essas 
modulações. Então, no momento de formação dessa diferença, os dois termos envolvidos se formam, conformam e, nesse momento específico (ou a todo momento), estão ali como potência, esperando para se realizarem. Uma coisa toca outra (e na verdade ambas são virtualidades de um mesmo) e temos então a possibilidade do duplo, do espelho, do outro-mesmo, do diferente-semelhante. No entanto, esse momento é que interessa aqui, o momento em que dois termos colidem e criam esse vazio, essa área opaca entre diferenciação e semelhança.

Retomemos o conceito de mímica, o que nos traz, também, de volta ao teatro da questão colonial: o anseio do colonizador frente ao colonizado. É nesse pequeno espaço que Bhabha parece comprimir essa questão tão longamente discutida da diferença. Em uma definição cristalina (do próprio Bhabha), "Colonial Mimicry is the desire for a reformed, recognizable other, as a subject of difference that is almost the same, but not quite. Which is to say, that the discourse of mimicry is constructed around an ambivalence; in order to be effective, mimicry must continually produce its slippage, its excess, its difference"5 (BHABHA, apud HUDDART, 2006). A mímica nada mais é do que uma repetição, uma cópia que tenta produzir a diferença. Semelhante a todos os conceitos e idéias aqui brevemente descritos, Bhabha quer encontrar sua especificidade, ainda que apenas os repita dentro de um contexto específico, menor (desde onde seja possível produzir determinada diferença).

O conceito de mímica para Bhabha parece estar atrelado a dois grandes pilares (se tentarmos uma entrada possível no "pensamento crítico" do autor): 1) metodologias pós-estruturalistas e 2) abordagem psicanalítica (HUDDART, op. cit., p. 4-5). No primeiro, segundo David Huddart, há certa noção de sujeito extraída de autores dos mais diversos, como Foucault, Deleuze e Derrida, da qual Bhabha teria se apropriado para pensar a diferença cultural. Importante ressaltar a ênfase que se dá sobre certa prática: não interessa o pensamento em si, mas uma metodologia e sua aplicação em determinado contexto. No segundo pilar, assentado em uma visão freudiana (ou seria lacaniana?), Huddart identifica apenas a utilização do vocábulo "anxiety" (ansiedade, angústia, inquietação), que, de maneira geral, seria o sentimento do colonizador frente a certas distensões entre (supostas) ilusão e realidade. Parece-me que há a intuição de certa abordagem psicanalítica ancorada em especulações a respeito dos sentimentos (talvez não seja a palavra certa ou a melhor maneira de dizer) dos dois pólos colocados em jogo: colonizadores e colonizados. A idéia geral da mímica, em termos psicanalíticos, é a de que a representação colonial trairia a idéia de identidade própria que o colonizador faz de si mesmo e a ansiedade gerada por isso abriria um espaço de resistência. Mas vimos que toda cópia, toda repetição, toda aparente dessemelhança prevê identidade, um espaço comum, que pode ser esse do patético, do reconhecimento agudo, como quando nos deparamos com um espelho ou com o riso desconcertante frente ao macaco de Franz Kafka - mas é sempre um "aberto", para utilizar um termo de Agamben, uma hesitação entre uma coisa e outra (um devir, uma linha de fuga).

Como uma espécie de conclusão prévia, podemos confrontar, então, o conceito freudiano-marxista de Bhabha (se é possível assim dizer) às Cinco proposições sobre a psicanálise, texto de Gilles Deleuze, de 1973 - que desdobra as discussões sobre psicanálise propostas em $O$ Anti-Édipo. A primeira proposição seria o risco político que reside na redução constante do inconsciente. No conceito de Bhabha, o desejo remonta sempre aos limites do teatro colonial, apresenta-se como demasiadamente orientado à sua traição, como se houvesse desejo demais. Deleuze propõe a criação de inconsciente, 
produção política, econômica e histórica, passando de um conceito a outro. Há que se notar que Bhabha propõe uma construção de sujeito nos moldes da produção do inconsciente tal qual sugere Deleuze, mas não escapa do risco político, uma vez que sua construção deve funcionar dentro de um limite proposto. A segunda proposição seria a observação de uma máquina já pronta, constituída previamente no intuito de não permitir uma fala, de sempre produzir um discurso já cooptado por um grupo de afinidades. Para Deleuze, a psicanálise faz tudo vibrar na freqüência do Édipo, da castração e do romance familiar; aqui, podemos dizer que Bhabha propõe esses moldes familiares para falar de mímica, uma vez que tudo é reconstituído dentro dessa espécie de drama familiar reproduzido nos moldes da questão colonial (pai-Inglaterracolonizador; filho-Índia-colonizado). A terceira proposição de Deleuze considera a psicanálise uma "máquina automática de interpretação" ("o que quer que se diga, o que se diz quer dizer outra coisa"): o que quer que seja produzido, a redução proposta pela idéia de uma máquina já pronta deve captar de forma a explicá-lo dentro de um contexto proposto. Trata-se da tentativa de explicar o que se produz produzindo outro texto, que não é necessariamente a coisa em si, mas que, ao constituir-se, apresenta-se com uma espécie de clivagem, o que ocorre quando Bhabha se apropria da arte colonial para falar de (interpretá-la como) resistência. Essa leitura pode reproduzir o espaço de resistência antecipado por Bhabha dentro de seu próprio conceito, o que, por sua vez, pode trazer consigo o perigo de seu excesso ou deslizamento, ou, mais radicalmente, ser ele mesmo uma recusa de si, por se tratar de um quase o mesmo, mas não exatamente daquilo que ele concebe como um discurso colonial mímico. A quarta proposição prevê uma "relação de forças particular", um contrato, que estabelece as partes e culmina, segundo o autor, no silêncio do analista. Essa divisão contratual, um tanto burguesa, segundo Deleuze, pode ser vista na separação proposta por Bhabha entre colonizador e colonizado, que culmina, ao meu ver, em uma espécie de silêncio consciencioso do colonizador, um silêncio que por si só é interpretativo, muito mais do que de aceitação além do que, o conceito só funciona diante da aparente passividade do colonizador, uma vez que ele é colocado, na divisão de forças, como uma espécie de sujeito fixo, a partir do qual a série mímica pode ser estabelecida. A última proposição fala da não-aceitação por parte do autor dessa perspectiva freudiano-marxista, por duas razões: primeiro, porque essa perspectiva "procede em geral por um retorno às origens", ou seja, há textos sagrados aos quais se deve sempre voltar (de Freud, de Marx); no caso de Bhabha, esse retorno às origens se dá a partir da capitalização da memória em função do desenvolvimento de uma luta de classes. Esse retorno, no entanto, é o que possibilita tanto a criação dos pólos opositores, quanto a utilidade do conceito de mímica. A segunda razão para não aceitar a visão freudiano-marxista em geral, e aqui tratamos de uma específica, a de Bhabha, é a constante tentativa de "conciliar duas economias: economia política e economia libidinal ou desejante" . Na visão de Deleuze, há apenas uma economia, que é já as duas. Em Bhabha, observa-se esse trânsito entre um suposto desejo (que já aparece atrelado à máquina interpretativa que constrói) do colonizador frente ao colonizado e suas repercussões políticas, ao passo que, para Deleuze, o desejo é já uma política.

\footnotetext{
${ }^{1}$ SANTIAGO, Silviano. A ameaça do lobisomem. In: Horizonte: Editora da UFMG, 2004.
} O cosmopolitismo do pobre. Belo 


\footnotetext{
2 "e os dois termos colidem - como parece acontecer hoje - as diferenças entre ser e nada, lícito e ilícito, divino e demoníaco também desvanecem, e em seu lugar algo surge, para o qual aparentemente não temos nem mesmo um nome" (tradução minha).

${ }^{3}$ DELEUZE, Gilles. A concepção de diferença em Bergson. In: A ilha deserta. São Paulo: Iluminuras, 2006.

4 "O texto de Cervantes e o de Menard são verbalmente idênticos, mas o segundo é quase infinitamente mais rico. (Mais ambíguo, dirão seus detratores, mas a ambigüidade é uma riqueza)" (tradução minha).

5 "Mímica Colonial é o desejo por um outro reformado e reconhecível, como sujeito da diferença que é quase o mesmo, mas não exatamente. Isso equivale a dizer que o discurso da mímica é construído em torno da ambivalência; para ser efetiva, a mímica deve sempre produzir seus deslizes, seus excessos, suas diferenças" (tradução minha).
}

\section{REFERÊNCIAS}

AGAMBEN, Giorgio. The open: Man and animal. Trad. Kevin Atell. California: Stanford University Press, 2004.

BATAILLE, Georges. O erotismo. Trad. João Benard da Costa. 2. ed. Lisboa: Moraes, 1980.

BHABHA, Homi K. O local da cultura. Trad. Mirian Ávila, Eliana Lourenço de Lima e Gláucia Renate Gonçalves. Belo Horizonte: Editora da UFMG, 1998.

BORGES, Jorge Luis. Pierre Menard, autor del Quijote. In: . Obras completas I. Buenos Aires: Emecé, 1996.

DELEUZE, Gilles. Diferença e repetição. Trad. Luiz Orlandi e Roberto Machado. Rio de Janeiro: Graal, 1988.

. A ilha deserta. Trad. Lia Guarino e Fernando Fagundes Ribeiro. São Paulo: Iluminuras, 2006.

; GUATTARI, Félix. Mil Platôs. V. 1. Trad. Suely Rolnik. São Paulo: Editora 34, 1996.

HUDDART, David. Homi Bhabha (Routledge Critical Thinkers). Nova Iorque: T\&F Informa, 2006.

KAFKA, Franz. Josefina, a cantora. São Paulo: Clube do Livro, 1977.

SANTIAGO, Silviano. A ameaça do lobisomem. In: . O cosmopolitismo do pobre. Belo Horizonte: Editora da UFMG, 2004. 